\title{
Caracterização anatômica, química e antibacteriana de folhas de Brunfelsia uniflora (manacá) presentes na Mata Atlântica
}

\author{
Maria Bernadete Gonçalves Martins, ${ }^{* 1}$ Rebeca de René Graf, ${ }^{1}$ Alberto J. Cavalheiro, ${ }^{2}$ \\ Selma D. Rodrigues ${ }^{1}$ \\ ${ }^{1}$ Universidade Estadual Paulista, Campus do Litoral Paulista, Unidade São Vicente, Praça Infante Dom \\ Henrique s/n, Parque Bitaru, 11330-900 São Vicente-SP, Brasil, \\ ${ }^{2}$ Universidade Estadual Paulista, Instituto de Química, Depto. de Química Orgânica, Campus de Araraquara, \\ Rua Francisco Degni, s/n, Bairro Quitandinha, 14800-900 Araraquara-SP, Brasil
}

\begin{abstract}
RESUMO: Brunfelsia uniflora é uma espécie pertencente à família Solanaceae conhecida popularmente como manacá e empregada em medicina popular, suas folhas são empregadas contra artrite, reumatismo, sífilis, picadas de cobra, febre amarela, e ainda como diurética e antitérmica. Objetivou-se realizar um estudo anatômico foliar, através de microscopia de luz e de eletrônica de varredura, bem como análises químicas do extrato foliar através de cromatografia e testes microbiológicos com os extratos foliares para atividade antibacteriana frente a Escherichia coli e Staphylococcus aureus. O material biológico foi coletado em área de Mata Atlântica, nas proximidades da cidade de São Vicente - SP. O estudo da anatomia foliar de Brunfelsia uniflora, evidenciou parênquima paliçádico com duas camadas celulares e o parênquima lacunoso com seis camadas de células; foi observada grande quantidade de drusas no parênquima clorofiliano e predominância de esclerênquima na região da nervura central da folha. A epiderme abaxial apresentou grande quantidade de estômatos, sendo estes quase que ausentes na epiderme adaxial. Estudos através de microscopia eletrônica de varredura permitiram evidenciar uma camada de cera epicuticular ornamental bem característica na epiderme adaxial da folha, predominância de estômatos paracíticos, presença de tricomas capitados e muitos tricomas peltados na epiderme abaxial da folha. A análise química evidenciou alguns picos nos cromatogramas que correspondem a grupos de substâncias que não puderam ser analisadas de forma qualitativa, mas que se pode inferir a ocorrência de derivados de ácido cafeico. Os testes microbiológicos obtidos apresentaram resultados negativos no controle das espécies de bactérias testadas, nas concentrações utilizadas.
\end{abstract}

Unitermos: Brunfelsia uniflora, Solanaceae, anatomia foliar, planta medicinal, constituintes químicos.

\begin{abstract}
Anatomical, chemical and antibacterial characterization of leaves of Brunfelsia uniflora (manacá) in the Atlantic Rainforest (Mata Atlântica)". Brunfelsia uniflora is a species that belongs to the family Solanaceae, popularly known as manacá. In popular medicine the leaves are used for arthritis, rheumatism, syphilis, snake bites, yellow fever, and even as a diuretic and anti-thermal. The main objective of this work was the anatomical study through optical and electronic scanning microscopy, chemical analysis and microbiological tests using Escherichia coli and Staphylococcus aureus and Brunfelsia uniflora leaves extracts. The plants were collected in the Atlantic Rainforest (Mata Atlântica), nearby the city of São Vicente, SP. Brunfelsia uniflora presented palisade parenchyma with two cellular layers and lacunary parenchyma with six cellular layers; large quantities of crystals in mesophyll and sclerenchyma were observed. The lower epidermis presented large quantities of stomata while they were almost absent in the adaxial epidermis. The electronic scanning microscopy showed the presence of paracitic stomata, a waxy layer ornamented in the adaxial epidermis as well as the presence of few trichomes in the central vein region in the abaxial surface. However, in the vein region the trichomes were absent. A chemical analysis showed evidence of some spectral peaks concerning the occurrence of caffeic acid derivatives. The microbiological tests presented negative results for the two species of bacteria.
\end{abstract}

Keywords: Brunfelsia uniflora, Solanaceae, leaf anatomy, medicinal plant, chemical analysis. 


\section{INTRODUÇÃO}

Brunfelsia uniflora é uma espécie pertencente à família Solanaceae conhecida popularmente como manacá. É uma planta nativa do sul e sudeste do Brasil e dos países limítrofes como Bolívia, Peru, Equador e Venezuela. No Brasil, a Mata Atlântica é o principal local de ocorrência dessa espécie. Este gênero é rico em alcalóides e muitas espécies do gênero podem ter atividade farmacológica ou possuírem alcalóides ou outros constituintes ativos (Plowman, 1977).

Possui folhas simples, quase glabras, de 4 a 7 $\mathrm{cm}$ de comprimento. Suas flores são tubulosas, solitárias, muito perfumadas, de cor inicialmente branca e, violeta após a fecundação. Os frutos são do tipo baga oblonga ou globosa (Lorenzi \& Matos, 2002).

A família Solanaceae tem importância econômica por conter espécies com atribuições ornamentais, medicinais e nutricionais (Reis, 2002, Corrêa et al., 2008; Quintans-Júnior et al., 2008). O gênero Brunfelsia inclui quarenta espécies tropicais americanas, as quais são importantes fontes de alcalóides e flavonóides (Brunner et al., 2000).

Estudos desenvolvidos em ratos através da administração oral de extratos aquosos de Brunfelsia uniflora, comprovaram sua atividade analgésica (Bettina et al., 1991).

A presença dos tricomas glandulares nos vegetais é um importante componente para resistência às plantas contra ataques de herbívoros, conferindo um caráter evolutivo para o estabelecimento das plantas. A densidade de tricomas no vegetal pode variar devido a fatores genéticos e fatores ambientais (Forkner \& Hare, 2000). Esses tricomas contêm ou secretam vários compostos fitoquímicos que podem alterar o paladar ou apresentar toxinas indesejáveis. Essas mesmas substâncias químicas têm sido estudas com o intuito de serem utilizadas com fins farmacológicos.

As indústrias farmacêuticas nacionais e internacionais, especialmente esta última, vêm buscando nas plantas da Mata Atlântica e na região Amazônica, essências, produtos e formulações para produção de medicamentos, vacinas e outras formas de terapia, visando à industrialização e comercialização em larga escala de princípios ativos identificados nestas plantas (Albuquerque \& Hanazaki, 2006: Araújo et al., 2008; Biavatti et al., 2007; Oliveira et al., 2007 Barbosa-Filho et al., 2007, 2008; Sousa et al., 2008).

Brunfelsia uniflora ou manacá apresenta registros de uso medicinal por algumas comunidades nativas. Na medicina popular, suas folhas são empregadas contra artrite, reumatismo, sífilis, picadas de cobra, febre amarela, e ainda como diurética e antitérmica. Há relatos que a planta seja utilizada como anestésica, abortiva, hipertensiva, laxativa e alucinógena quando utilizadas em altas concentrações (Agra et al., 2007).

À medida que nossas fontes não-renováveis de energia se aproximam da exaustão e os preços se elevam, tem-se tornado cada vez mais importante encontrar meios de produzir moléculas complexas com menor gasto. Além disso, a vasta maioria das plantas nunca foi examinada ou testada para determinar sua utilidade (Raven et al., 2001).

A proposta deste estudo é encontrar uma fonte de recurso natural que forneça dados para serem utilizados na farmacologia, medicina popular, ou em qualquer outro setor industrial, como indústria alimentícia, cosmetologia, etc.

\section{MATERIAL E MÉTODOS}

As folhas de Brunfelsia uniflora, foram coletadas em área natural da Mata Atlântica, nas proximidades da encosta da bacia da cidade de São Vicente-SP, na orla da praia, em maio de 2006, registrada no herbário da ESALQ/USP sob número 79923 da exsicata.

\section{Preparação do laminário histológico para microscopia de luz}

Com a finalidade de se estudar a histologia da lâmina foliar, foram utilizadas folhas adultas, colhidas no estágio reprodutivo da planta. O preparo do material para obtenção do laminário histológico para microscopia de luz constituiu-se basicamente de processos usuais utilizados em microtomia, que incluíram: fixação em FAA $70 \%$ por 24 horas, desidratação em série alcoólica (etílica), infiltração em resina sintética (G.M.A.), emblocamento, seccionamento, coloração e montagem de lâminas permanentes. As peças incluídas em resina sintética foram seccionadas em micrótomo rotativo, obtendo-se secções transversais da lâmina foliar e da nervura principal, com $4 \mu \mathrm{m}$. Foi utilizado o corante Azul de Toluidina 1\% com Borato de Sódio 1\%, em 100 $\mathrm{ml}$ de água destilada (O’Brien et al., 1964).

\section{Estudo de microscopia eletrônica de varredura}

O material foi fixado em uma solução de Karnovsky modificado, composta por paraformoldeído $4 \%$, glutaraldeído $0,5 \%$, em tampão cacodilato de sódio, $\mathrm{pH}$ 7,2, 0,1 $\mathrm{M}$ e água destilada, por uma noite no vácuo. Em seguida, foram feitas três lavagens com cacodilato $0,05 \mathrm{M}$, com a duração de dez minutos cada e realizada para melhor visualização da imagem uma pósfixação com tetróxido de ósmio $\left(\mathrm{OsO}_{4}\right)$ por duas horas. Em seguida, o material foi desidratado com acetona seguindo série de concentrações: $30 \%, 50 \%, 70 \%, 90 \%$ e $100 \%$.

$\mathrm{O}$ material foi levado à secagem até o ponto crítico e fixado a um suporte através de um adesivo condutor e em seguida metalizado (Danilatos, 1988).

Análise química 
Pesagem de $1,00 \mathrm{~g}$ de folhas secas e moídas de Brunfelsia uniflora em erlenmeyer (125 ml). Adição de $50 \mathrm{ml}$ de EtOH (solvente). Sonicação em 30 minutos. Filtração. Repetição: Adição de $50 \mathrm{ml}$ de EtOH, Sonicação em 30 minutos e Filtração. Retirada de duas alíquotas de $5 \mathrm{ml}$. Secagem das alíquotas.

\section{Análise cromatográfica}

Antes de ser analisado por cromatografia líquida de alta eficiência (CLAE-DAD) e cromatografia de camada delgada (CCD), uma alíquota do extrato foi submetida a um tratamento preliminar, etapa que envolve a eliminação de substâncias com caráter mais apolar, incluindo grande parte dos pigmentos. Pesagem de $1,5 \mathrm{~g}$ de $\mathrm{C}-18(40-63 \mu \mathrm{m})$ e preparação de um cartucho com uma coluna de vidro $(0,9 \mathrm{~cm}$ diâmetro $)$. Condicionamento do cartucho com $3,0 \mathrm{ml}$ do eluente $\mathrm{MeOH}: \mathrm{H}_{2} \mathrm{O}$ (95:05). Secagem do cartucho com ar comprimido. Solubilização do extrato em $1,0 \mathrm{ml}$ do eluente. Aplicação do extrato na coluna e eluição da amostra com 5,0 ml do eluente. Filtração da amostra em membrana Milipore ${ }^{\circledR}(0,45 \mu \mathrm{m})$ e acondicionamento em frasco para injeção automática (CLAE) e para a CCD. Obteve-se assim uma fração bruta e outra mais polar.

As alíquotas da fração bruta e da fração polar foram analisadas em CCD com fase móvel de AcOET em cubas de vidros. As placas foram analisadas no visível, no UV (254 nm) e reveladas com anisaldeído (Geral) e Dragendorff (Alcalóides).

A fração polar foi analisada em CLAE-DAD para obtenção do perfil cromatográfico. As condições cromatográficas para CLAE-DAD utilizadas nesse estudo estão descritas na Tabela 1.

\section{Confecção de lâminas de folhas diafanizadas}

O estudo do sistema vascular de órgãos de plantas jovens e de folhas adultas tem sido executado usando-se não somente métodos anatômicos e citológicos, mas também técnicas de clarificação e coloração. O material foi colocado em $\mathrm{NaOH} 5 \%$, trocando a solução até que a folha ficasse amarela, após lavagem em água, foi colocado em hipoclorito de sódio $20 \%$ por aproximadamente 20 minutos. Utilizou-se azul de toluidina aquosa até corar (O'Brien et al., 1964). O material foi desidratado em série alcoólica (etílica), passando-se pelo xilol e realizando-se a montagem das lâminas (Felippe \& Alencastro,1966).

\section{Testes microbiológicos}

A caracterização prévia de possível efeito antimicrobiano do extrato do vegetal em referência, foi realizado a partir da preparação de suspensão homogeneizada a $1 / 10$ em salina fosfatada tamponada estéril, para semeadura em orifícios preparados em placas de brain heart infusion agar (oxoid $\AA$ ), previamente inoculadas com as linhagens teste duplicadas, contendo o meio de cultura. Foram adicionadas $\mathrm{v} / \mathrm{v}$ de concentrações seriadas de $1 \%, 2 \%, 4 \%, 8 \%, 16 \%$ e $32 \%$ do homogeneizado e semeadas em orifícios com $100 \mu 1$ de uma suspensão de $1 \times 10^{7}$ unidades formadoras de colônias de uma linhagem bacteriana de Escherichia coli (U.177) e de Staphylococcus aureus (S.4260), patogênicas de referência departamental (Departamento de microbiologia e imunologia - IBB - Botucatu UNESP). As placas após o inóculo foram incubadas durante $18 \mathrm{~h}$ a $37^{\circ} \mathrm{C}$, sendo observado a ocorrência ou não de efeito antibacteriano do homogeneizado frente à linhagem em estudo. $\mathrm{O}$ resultado positivo permitirá a continuação de ensaios específicos conforme metodologia explicitada no projeto original, quanto à determinação da concentração inibitória mínima e a respectiva curva de morte de cada linhagem.

\section{Análises}

Microscopia de Luz. Os estudos de Microscopia de luz visaram a análise histológica das camadas celulares, assim como a cutícula, epiderme, parênquima (paliçádico e lacunoso) e estômatos. Foi também analisada a presença de glândulas secretoras e a classificação quanto o tipo glandular. As análises acima descritas foram feitas em ambas as superfícies foliares (abaxial e adaxial). A análise microscópica foi registrada através de fotomicrografia.

Microscopia Eletrônica de Varredura. As análises da superfície foliar, descrição e identificação do tipo de estruturas secretoras das folhas foram realizadas nas superfícies abaxial e adaxial e também foram documentadas em fotomicrografias.

Análise Química. Os resultados foram analisados de forma qualitativa e comparativa com os estudos feitos para a mesma família e mesmo gênero.

Testes Microbiológicos. Os resultados foram avaliados inicialmente de forma qualitativa para verificar se existe ou não uma atividade inibitória da planta com relação às linhagens de bactérias selecionadas. Em caso de resultado positivo, será realizada uma análise quantitativa para determinação da concentração inibitória mínima (CIM) do extrato foliar de B. uniflora.

\section{RESULTADOS E DISCUSSÃO}

\section{Microscopia de luz}

O corte transversal da folha evidenciou $o$ parênquima paliçádico com 1-2 camadas de células e o parênquima lacunoso com 5-6 camadas (Figura 1C). Havia grande quantidade de drusas no parênquima clorofiliano (Figura 1B). Na região da nervura principal, observou-se a presença de fibras de esclerênquima 
circundando o feixe vascular. Os feixes eram bicolaterais (Figura 1A-D). Havia grande quantidade de estômatos na epiderme abaxial (Figura 1A-C), sendo predominantes os do tipo paracítico ou rubiáceo $\mathrm{Na}$ epiderme adaxial, ocorrem poucos estômatos distribuídos de forma aleatória (Figura 1A-C).

De acordo com Metcalfe \& Chalk (1957), folhas anfistomáticas são comuns em Solanaceae, embora Cosa de Gastiazoro (1991), tenha descrito folhas hipoestomáticas em algumas espécies da família. Em B. uniflora os estômatos são abundantes na epiderme abaxial e raros e esparsos na epiderme adaxial. Em Petunia sp (Solanaceae) as folhas são anfistomáticas e os tricomas presentes são uniseriados, enquanto no manacá, os tricomas que foram raramente encontrados, estavam na epiderme abaxial.

Mccauley \& Evert (1988), estudando folhas de Solanum tuberosum L. cv. Russet Burbank, observou que o mesofilo possui parênquima paliçádico com 1-2 camadas de células e parênquima e lacunoso com 3-4 camadas de células, bem como a presença de tricomas nas superfícies adaxial e abaxial e feixes bicolaterais, além de estômatos do tipo ranunculáceos ou anomocíticos.

\section{Microscopia eletrônica de varredura}

$\mathrm{Na}$ epiderme adaxial foram observados depósitos de cera epicuticular, distribuídos em vários mosaicos de padrão estriado, visualizando uma ornamentação característica (Figura 2A); na epiderme abaxial, tricomas do tipo peltado, sendo que a cabeça da glândula era constituída por oito células secretoras (Figura 2D). Havia também estômatos paracíticos, onde as células anexas são paralelas ao eixo do estômato (Figura 2C). As células epidérmicas mostraram-se com contorno sinuoso (Figura 2C). Mccauley \& Evert (1988) realizaram estudos sobre a anatomia foliar de Solanum tuberosum (Solanaceae) e verificaram que o contorno das células epidérmicas era sinuoso, assim como foi verificado em Brunfelsia uniflora.

\section{Análise química}

O extrato etanólico de folhas de Brunfelsia, após tratamento preliminar por extração em fase sólida (EFS-C18) para eliminação de interferentes lipofílicos, foi analisado por CLAE-DAD, munido de coluna de fase reversa $\mathrm{C} 18$. O objetivo desta análise foi avaliar a complexidade do perfil químico deste extrato e obter informações preliminares sobre classes de substâncias presentes, através dos espectros no UV obtidos para os principais picos cromatográficos. Os cromatogramas obtidos para o extrato de manacá, registrados em 254 e $270 \mathrm{~nm}$ (Figura 3), apresentam picos intensos no início do cromatograma (2-4 $\mathrm{min})$. Os espectros no UV destes picos não puderam ser analisados. Na região compreendida entre 19 a 23 min (figura 4) foram observados picos representativos de substâncias menos polares e com espectros no UV similares e indicativos da presença de sistema de ligações duplas (provavelmente um sistema triênico) conjugadas nessas substâncias. $\mathrm{Na}$ região compreendida entre 8 e 14 min eluiram várias substâncias com polaridade intermediária. Os espectros no UV obtidos para os 8 picos mais intensos indicam a ocorrência de pelo menos três classes de substâncias (1 e 4, 2 e 3,5 a 8 ) nessa região do cromatograma. Para obtenção de informação qualitativa mais robusta, prevê-se o fracionamento do extrato em cinco grupos de substâncias de polaridades diferentes, seguida da aquisição de dados de RMN de ${ }^{1} \mathrm{H}$ pelo menos. Mesmo assim, considerando espectros no UV dos metabólitos secundários já isolados de espécies de Brunfelsia, foi possível inferir a ocorrência de derivados de ácido cafeico, como por exemplo, o ácido clorogênico, por possuirem espectros no UV semelhantes aquele obtido para o pico 1 ( $\lambda_{\text {max }}$ em 300 e $325 \mathrm{~nm}$ ) coumarinas (pico $4, \lambda_{\max } 330 \mathrm{~nm}$ ). Para os demais picos cromatográficos ainda não foi possível propor nenhuma identidade. Friedman (1992), observou ácido clorogênico em batatas processadas a fresco, através de espectrofotometria por ultravioleta. Com relação aos alcalóides, Gellert et al. (1978), observaram a presença de alcalóides em Brunfelsia hopeana; neste trabalho como não foi realizado procedimento de extração, tratamento da amostra e análise cromatográfica em condições específica para esse grupo de substâncias, nada pode ser concluído sobre sua presença ou ausência nessa amostra.

Mors \& Robeiro (1957), realizaram estudos, evidenciando que a maioria das espécies do gênero Brunfelsia, possui alguns grupos de alcalóides, como a escopoletina (6-metoxi-7-hidroxicoumarina), que também já foi encontrado em outras famílias (Carvalho et al., 2006; Pinto et al., 2008; Razavi et al., 2008).

Wollenweber \& Dorr (1995) verificaram a presença de diferentes grupos de flavonóides em Browallia grandiflora, Chamaesaracha sordida, Nicotiana tabacum, Petunia surfina e Salpiglossis sinuata, todas espécies da família Solanaceae. Este estudo, portanto, serve de base para que a presença de flavonóides em $B$. uniflora seja testada, visto que esse é um grupo frequentemente encontrado em espécies da família.

Do ponto de vista farmacológico, alguns flavonóides possuem propriedades interessantes, como benefícios para a permeabilidade dos capilares. Além do mais, flavonóides tem demonstrado possuir atividade diurética, hepatoprotetora, antiinflamatória, anti-radicais livres e até mesmo propriedades antibacterianas (Bruneton, 1983, apud Brunner, 2000). Brunner et al. (2000), determinaram a estrutura química de um flavonóides isolado de Brunfelsia grandiflora, sugerindo assim, que um dos possíveis compostos químicos de $B$. uniflora possa ser do grupo dos flavonóides. Levantamento bibliográfico através 
do SciFinder indicou a existência de vários estudos fitoquímcos de espécies de Brunfelsia. As principais classes de metabólitos secundários descritas para essas espécies vegetais incluem saponinas esteroidais, ácidos graxos ciclopropenóides, alcalóides, coumarinas e ácido clorogênico. Silva et al. (2003), realizaram estudos e observaram a ocorrência de flavonas, flavonóis e glicosídeos em espécies do gênero Solanum, evidenciando que diferentes espécies deste gênero possuem diferentes grupos de flavonóides. Mais uma vez, um trabalho sugere que a presença de flavonóides deva ser testada para Brunfelsia uniflora, em vista à grande ocorrência deste grupo químico em espécies da família Solanaceae.

\section{Diafanização}

O padrão de venação de $B$. uniflora é do tipo pinado

Tabela 1. Condições cromatográficas para CLAE-DAD.

\begin{tabular}{|c|c|}
\hline Parâmetro & Condição \\
\hline Coluna & Supelcosil $®, C-18 \mu \mathrm{m}, 250 \times 4,6 \mathrm{~mm}$ \\
\hline Fase móvel & Gradiente Linear \\
\hline A (Tampão Fosfato) & $5-100 \%$ de $\mathrm{B}(30 \mathrm{~min})$ \\
\hline B (ACN - acetato de nitrila) & $100 \%$ de $\mathrm{B}(30 \mathrm{~min})$ \\
\hline Tempo de equilíbrio (min) & $\begin{array}{l}5 \% \mathrm{de} \text { B }(30 \mathrm{~min}) \mathrm{I}=63 \mathrm{~min} \\
15\end{array}$ \\
\hline Fluxo (mL/min) & 1 \\
\hline$\lambda(\mathrm{nm})$ & 254 \\
\hline Volume de injeção $(\mu \mathrm{l})$ & 20 \\
\hline
\end{tabular}

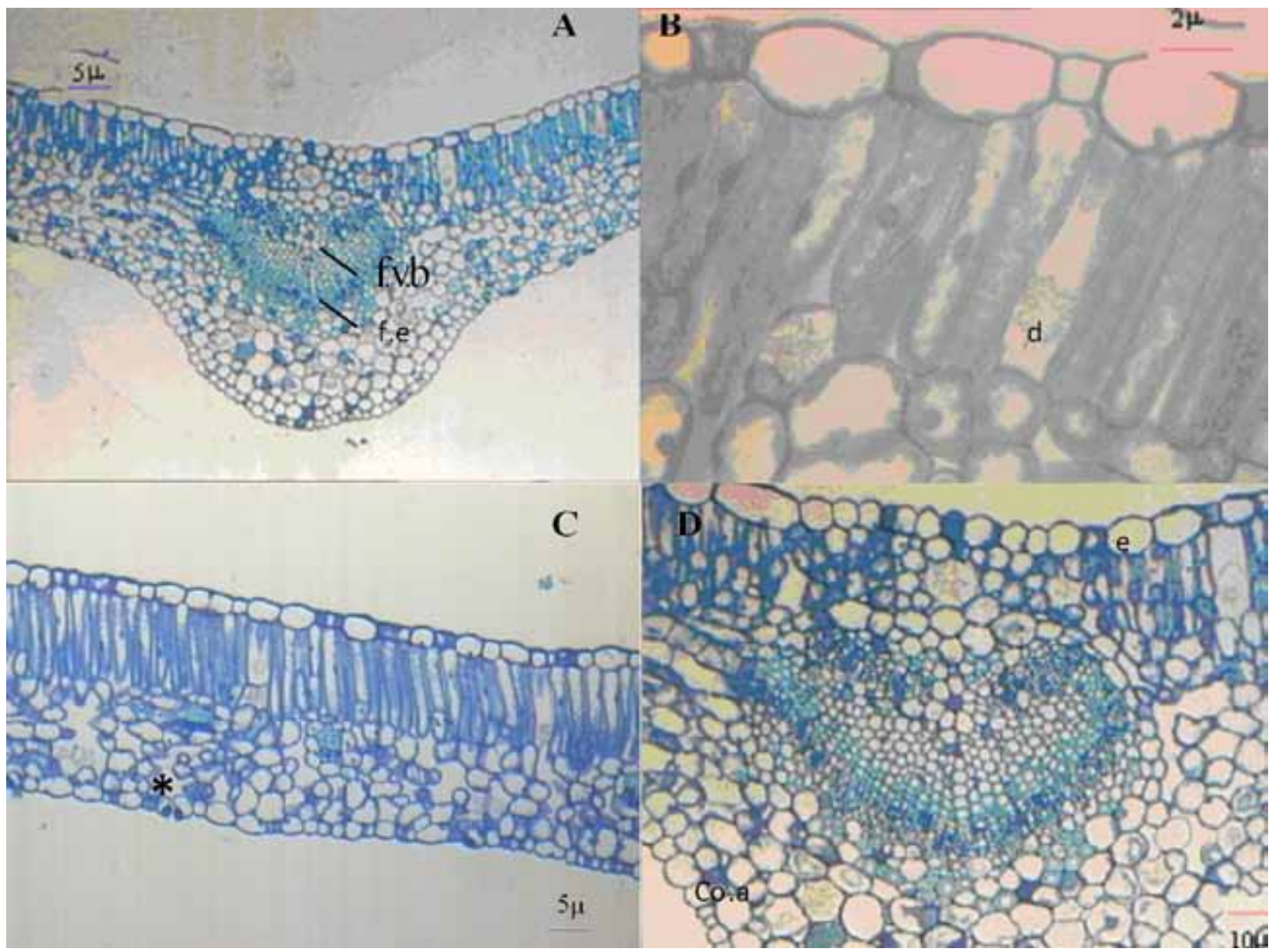

Figura 1. Corte transversal da folha de Brunfelsia uniflora (Solanaceae). A - Detalhe da folha na região da nervura central. B - Detalhe do parênquima paliçádico com drusas. C - Detalhe do limbo foliar com grande quantidade de estômatos na epiderme abaxial. D - Detalhe da nervura central da folha. E = epiderme; f.v.b = feixe vascular bicolateral; f.e = fibras de esclerênquima; $\mathrm{d}=$ drusas; c.a = colênquima anelar; $*$ = camada subestomática. 

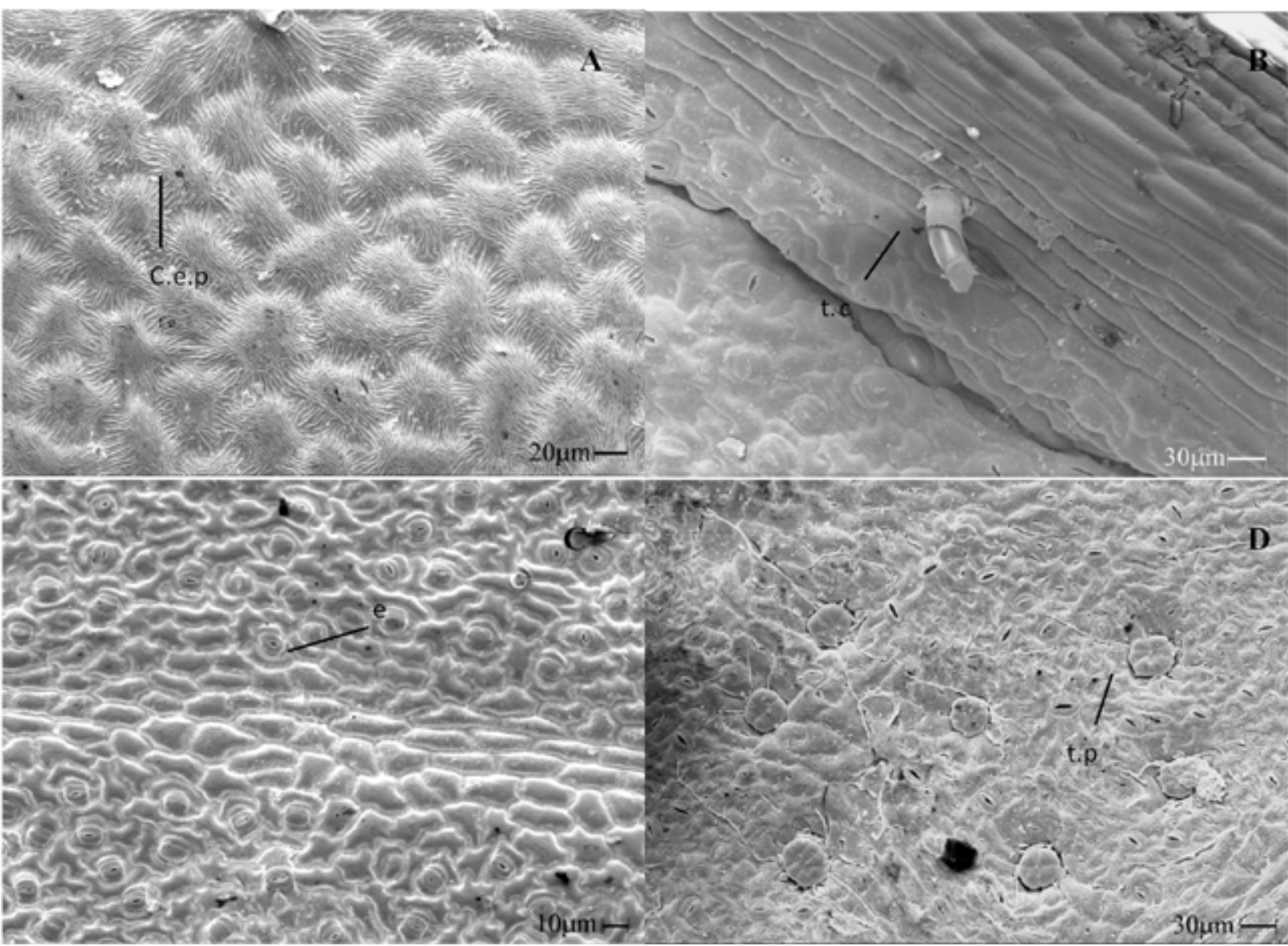

Figura 2. Micrografia eletrônica de varredura. A - Superfície adaxial da folha evidenciando cera epicuticular ornamental (mosaicos). B - Detalhe da nervura principal da folha na superfície abaxial. C - Superfície abaxial da folha. D - Superfície abaxial da folha mostrando a presença de vários tricomas peltados. C.E = cera epicuticular; T.C $=$ Tricoma capitado; $\mathrm{E}=$ Estômato; T.P = Tricoma peltado.

por apresentar uma única nervura central. O espaçamento entre as nervuras secundárias é irregular, pois não segue um padrão. O ângulo formado pelas nervuras secundárias em relação à nervura central é do tipo uniforme, pois se mantém constante sem sofrer aumentos ou reduções em relação à base foliar. B. uniflora possui nervuras intersecundárias finas. As reticulações encontradas nessa planta são classificadas como aleatórias, onde, as anastomoses ocorrem com nervuras secundárias ou terciárias em ângulos aleatórios. O curso das nervuras terciárias é ramificado, pois, são orientadas em direção à margem da folha. A areolação (processo de formação das menores áreas circundadas por nervuras) segue o padrão moderadamente desenvolvido, pois o tamanho das aréolas é irregular, com moderada variação de tamanho e com aréolas de 3 e 4 lados (Figura 6A). A venação marginal é composta por laços incompletos, pois estão livres em relação à margem e é semicraspedódroma, pois as nervuras secundárias se ramificam próximo à margem, sendo que uma das ramificações termina na margem e a outra se junta à nervura secundária sobrejacente (Figura 6B)

\section{Testes microbiológicos}

Com relação aos testes microbiológicos do ensaio preliminar foi possível verificar que Brunfelsia uniflora não apresentou nenhuma atividade inibitória para Escherichia coli nem para Staphylococcus aureus em nenhuma das concentrações testadas, sendo o crescimento das bactérias uniforme e sobre toda a superfície da placa.

Morais Filho (2001), avaliou a atividade antimicrobiana de extrato foliar de Phisalis angulata (Solanaceae) sobre linhagens de Escherichia coli e Estaphylococcus aureus. Verificou, entretanto que para ambas as bactérias, $P$. angulata não apresentou atividade inibitória, sendo esse resultado semelhante ao obtido para B. uniflora.

Digrak et al. (2001), testaram a atividade antimicrobiana e antifúngica de extratos foliares de Nicotina rustica (Solanaceae). Para E. coli, N. rustica não apresentou nenhuma atividade inibitória, entretanto para $E$. aureus houve inibição do crescimento, com formação de alos de até $15 \mathrm{~mm}$. Este estudo também forneceu resultados relevantes com relação a Candida 

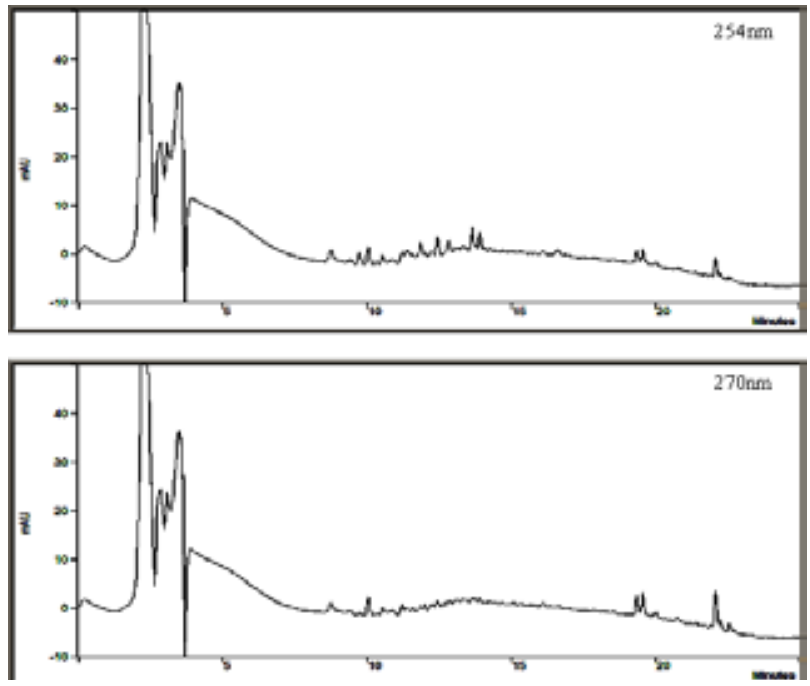

Figura 3. Cromatogramas do extrato etanólico de folhas de Brunfelsia, obtidos em CLAE-DAD e registrados a 254 e 270 $\mathrm{nm}$.

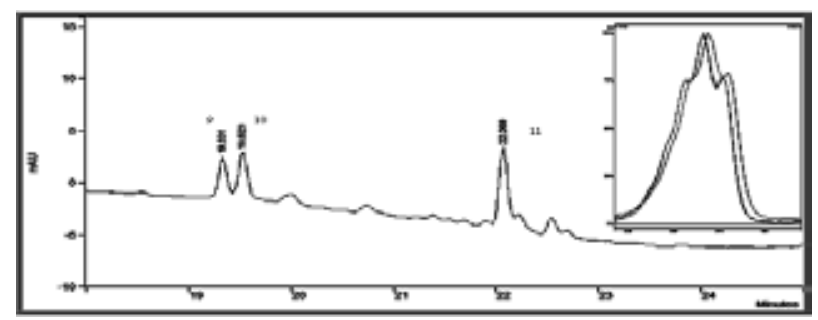

Figura 4. Expansão do cromatograma do extrato bruto de folhas de Brunfelsia. Em destaque os espectros no UV dos picos 9, 10 e 11, provavelmente relacionados a substâncias com grupos triênicos conjugados.
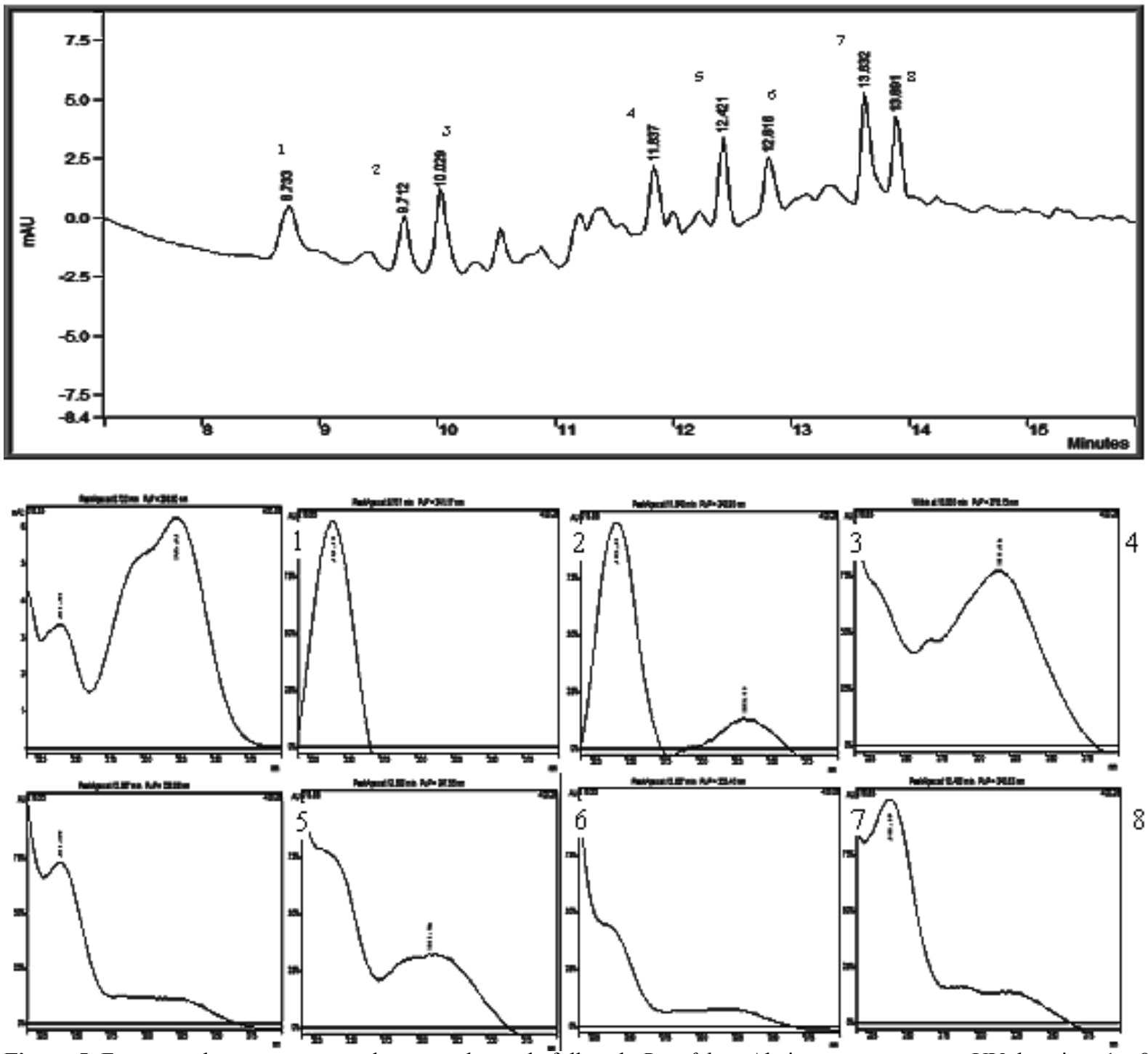

Figura 5. Expansão do cromatograma do extrato bruto de folhas de Brunfelsia. Abaixo os espectros no UV dos picos 1 a 8 , na região de 220 a $400 \mathrm{~nm}$. 
A - Detalhe da nervura principal. B - Detalhe das nervuras evidenciando a região do bordo.

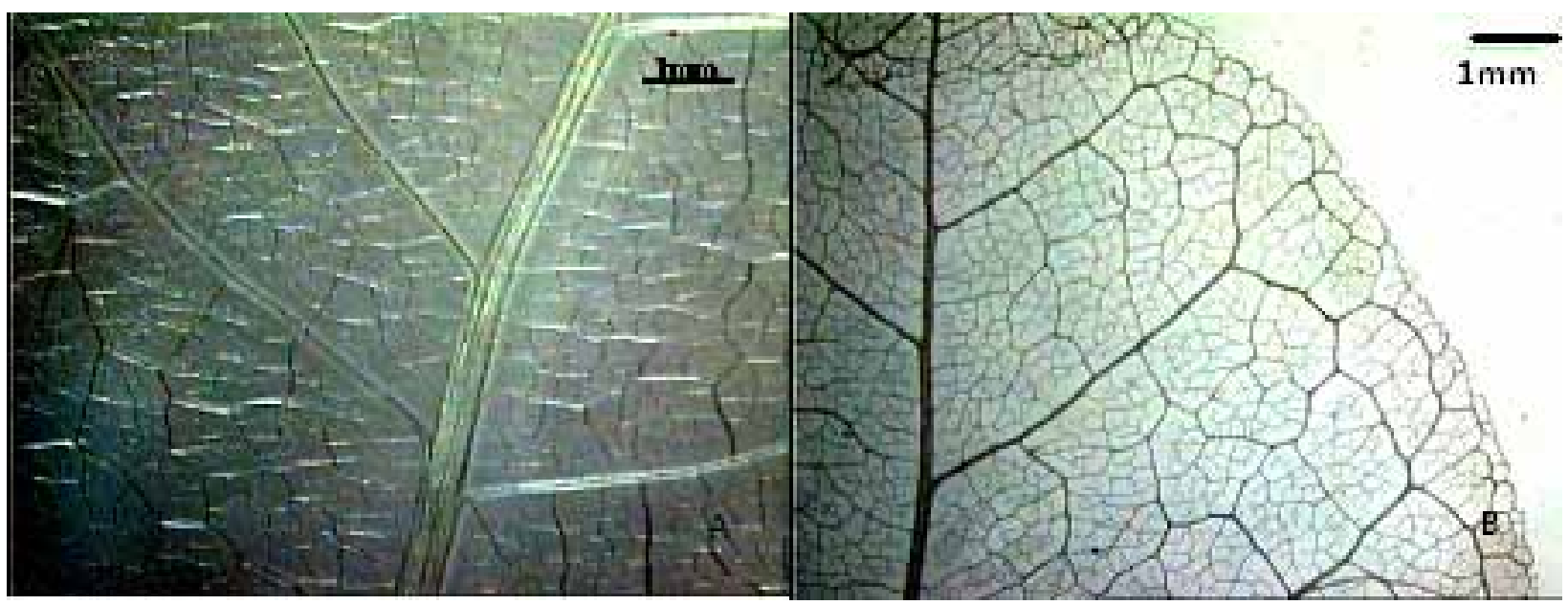

Figura 6. Folha de Brunfelsia uniflora diafanizada.

albicans (formação de alos de $13 \mathrm{~mm}$ ). Isso pode sugerir que Brunfelsia uniflora possa ser, em estudos posteriores, testada com diferentes espécies de bactérias e leveduras, por exemplo, C. albicans.

Também é importante ressaltar que a extração de substâncias capazes de apresentar alguma atividade fica sujeita a variação em função do solvente utilizado durante a extração. Sendo assim, neste estudo, $B$. uniflora não apresentou atividade inibitória para $E$ coli e $S$. aureus. Entretanto, a mesma planta ainda pode ser testada para as mesmas bactérias, porém com uso de diferentes solventes durante a extração.

\section{AGRADECIMENTOS}

À FAPESP, pelo apoio concedido. À Profa. Dra. Beatriz Apezzato da Glória ( pela concessão do micrótomo no Laboratório de Anatomia Vegetal e ao Prof. Dr. Kitajima pela utilização do Centro de Microscopia Eletrônica ESALQ-USP - Piracicaba, SP).

\section{CONCLUSÕES}

Através de estudos anatômicos; cromatográficos e microbiológicos do extrato foliar de Brunfelsia uniflora, pode-se concluir que: $\mathrm{O}$ parênquima paliçádico, apresenta-se com 1-2 camadas de células e o parênquima lacunoso com 5-6 camadas de células; há grande quantidade de drusas no parênquima clorofiliano; presença de feixes bicolaterais circundados por fibras de esclerênquima; a folha é anfiestomática, com predominância de estômatos paracíticos na epiderme abaxial; presença de tricomas do tipo peltado na epiderme abaxial, sendo que a cabeça da glândula é constituída por oito células secretoras; na epiderme adaxial, há depósitos de cera epicuticular, formando mosaicos de padrão estriado, caracterizando uma ornamentação; propõe-se a ocorrência de derivados do ácido cafeico, como por exemplo do ácido clorogênico através da análise de extratos foliares por cromatografia; não foi verificada atividade antibacteriana dos extratos foliares para Escherichia coli, nem para Staphylococcus aureus, nas concentrações e nas cepas utilizadas.

\section{REFERÊNCIAS}

Agra MF, França PF, Barbosa-Filho JM 2007. Synopsis of the plants known as medicinal and poisonous in Northeast of Brazil. Rev Bras Farmacogn 17: 114140.

Albuquerque UP, Hanazaki N 2006. As pesquisas etnodirigidas na descoberta de novos fármacos de interesse médico e farmacêutico: fragilidades e pespectivas. Rev Bras Farmacogn 16(Supl.): 678-689.

Araújo EL, Randau KP, Sena-Filho JG, Pimentel RMM, Xavier HS 2008. Acanthospermum hispidum DC (Asteraceae): perspectives for a phytotherapeutic product. Rev Bras Farmacogn 18 (Supl.): 777-784.

Barbosa-Filho JM, Nascimento-Júnior FA, Tomaz ACA, Athayde-Filho PF, Silva MS, Cunha EVL, Souza MFV, Batista LM, Diniz MFFM 2007. Natural products with antileprotic activity. Rev Bras Farmacogn 17: 141-148.

Barbosa-Filho JM, Alencar AA, Nunes XP, Tomaz ACA, Sena-Filho JG, Athayde-Filho PF, Silva MS, Souza MFV, da-Cunha EVL 2008. Sources of alpha-, beta, gamma-, delta- and epsilon-carotenes: A twentieth century review. Rev Bras Farmacogn 18: 135-154.

Bettina MR, Pereira EFR, Gonçalves LC, Pereira NA 1991. Pharmacological screening of plants recommended by folk medicine as anti-snake venom. I. analgesic and anti-inflamatory activities. Mem Inst Oswaldo Cruz 86: 203-205.

Biavatti M, Marensi V, Leite SN, Reis A 2007. Ethnopharmacognostic survey on botanical 
compendia for potential cosmeceutic species from Atlantic Forest. Rev Bras Farmacogn 17: 640-653.

Brunner G, Burger U, Castioni P, Kapetanidis I, Christen P 2000. A novel acylated flavonol glycoside isolated from Brunfelsia grandiflora ssp. structure elucidation by gradient accelerated NMR Spectroscopy at $14 \mathrm{t}$. Phytochem Anal 11: 29-33.

Carvalho MG, Alves CCF, Werle AA, Braz-Filho R 2006. Metabólitos especiais isolados de Laseguea erecta (Apocynaceae). Rev Bras Farmacogn 16: 497-500.

Corrêa MFP, Melo GO, Costa SS 2008. Substâncias de origem vegetal potencialmente úteis na terapia da Asma. Rev Bras Farmacogn 18 (Supl.): 785-797.

Cosa de Gastiazoro MT 1991. Estudio morfo-anatómico de órganos vegetativos em Cestroideae (Solanaceae). I. Tribu Nicotianeae. Kurtziana 21: 111- 150.

Danilatos GD 1988. Foundations of environmental scanning electron microscopy. Adv Electron Electron Phys 71: 109-250.

Digrak M, Alma M, Hakk T 2001. Antibacterial and antifungal activities of Turkish medicinal plants. Pharm Biol 39: 346-350.

Felippe GM, Alencastro FMMR 1966. Contribuição ao estudo da nervação foliar das compositae dos cerrados. I. Tribus Helenieae, Heliantheae, Inuleae, Mutisieae e Senecioneae. Ann Acad Bras Cienc 38: 125-157.

Forkner RE, Hare JD 2000. Genetic and environmental variation in acyl glucose ester production and glandular and nonglandular trichome densities in Datura wrightii. J Chem Ecol 26: 2801-2823.

Friedman M 1992. Chlorogenic acid content of fresh and processed potatoes determined by ultraviolet spectrophotometry. J Agric Food Chem 40: 21522156.

Gellert E, Chaubal MG, Iyer RP 1978. The alkaloids of Brunfelsia hopeana (Hock) Benth. 11 Symp. Pap. - Iupac Int. Symp. Chem. Nat. Prod. Wollongong, Australia.

Lorenzi H, Matos FJA 2002. Plantas Medicinais No Brasil, Nativas e Exóticas. Nova Odessa: Ed. Plantarum.

Mccauley MM, Evert RF 1988. The anatomy of the leaf of potato, Solanum tuberosum L. Russet Burbank. Bot Gaz 149: 179-195.

Metcalfe C, Chalk L 1957. Anatomy of the Dicotyledons. Oxford: Claredon Press.

Morais Filho ZB 2001. Constituintes químicos e atividade antibacteriana do extrato etanólico de folhas de Phisalis angulata L. (Solanaceae). Rio de Janeiro, 169p. Dissertação de Mestrado - Universidade Federal do Rio de Janeiro.

Mors WG, Robeiro O 1957. Occurence of scopoletin in the genus Brunfelsia. J Org Chem 22: 978.

O'Brien TP, Feder N, Mccully ME 1964. Polychromatic staining of plant cell walls by toluidine blue. Protoplasma 59: 368-373.

Oliveira FQ, Gobira B, Guimarães C, Batista J, Barreto M, Souza M 2007. Espécies vegetais indicadas na odontologia. Rev Bras Farmacogn 17: 466-476.

Pinto DS, Tomaz ACA, Tavares JF, Tenório-Souza FH, Silva Dias CS, Braz-Filho R, Cunha EVL, Secondary metabolites isolated from Richardia brasiliensis Gomes (Rubiaceae). Rev Bras Farmacogn 18: $367-$ 372.
Plowman T 1977. Brunfelsia in Ethnomedicine. Bot Mus Leaf 25: 289-319.

Quintans-Júnior LJ, Almeida JRGS, Lima JT, Nunes XP, Siqueira JS, Oliveira LEG, Almeida RN, AthaydeFilho PF, Barbosa-Filho JM 2008. Plants with anticonvulsant properties - a review. Rev Bras Farmacogn 18 (Supl.): 798-819.

Raven PH, Evert RF, Eichhorn SE 2001. Biologia Vegetal. Rio De Janeiro: Ed. Guanabara Koogan.

Razavi SM, Nazemiyeh H, Hajiboland R, Kumarasamy Y, Delazar A, Nahar L, Sarker SD 2008. Coumarins from the aerial parts of Prangos uloptera (Apiaceae). Rev Bras Farmacogn 18: 1-5.

Reis C, Sajo MG, Sthmann 2002. Leaf structure and taxonomy of Petunia and Calibrachoa (Solanaceae). Braz Arch Biol Technol 45: 59-66.

Silva TMS, Carvalho MG, Braz-Filho R, Agra MF 2003. Ocorrência de flavonas, flavonóis e seus glicosídeos em espécies do gênero Solanum (Solanaceae). Quim Nova 26: 517-522.

Sousa FCF, Melo CTV, Citó MCO, Félix FHC, Vasconcelos SMM, Fonteles MMF, Barbosa-Filho JM, Viana GSB 2008. Plantas medicinais e seus constituintes bioativos: Uma revisão da bioatividade e potenciais benefícios nos distúrbios da ansiedade em modelos animais. Rev Bras Farmacogn 18: 642-654.

Wollenweber E, Dorr M 1995. Exudate flavonoids in some Solanaceae. Biochem Syst Ecol 23: 457-458. 